\title{
ELEMENTS OF LOCAL AUTONOMY AND NEW TECHNOLOGY IN URBAN REVITALIZATION PROCESS
}

\author{
Anastasia Stefanita ${ }^{1}$
}

\begin{abstract}
The article aims to present the concept of the urban revitalization in relation with the new information technologies. The actuality of the topic relates from the importance of information tools in all processes of human activity, including the administrative and participatory one. The urban revitalization is presented as a dimension of the decisional local autonomy of public authorities of the cities/municipalities. The paper is based on the on-going activities of the bilateral Polish Moldavian "Revitalization Project". The e-tools become a new dimension of the classical "renewal" concept, transforming in this way the revitalization process in a modern one and upgrading it to a higher level. Because of the rapid development of the information society, the revitalization processes undergo changes and gains new meaning. The expectations of citizens as well as the activities of local public authorities imply new standards, especially in terms of information technologies.
\end{abstract}

\section{Definition and concept of urban revitalization}

\subsection{The notion of urban revitalization}

There are several terms and definitions of urban revitalization. In the United Kingdom the process is called „urban regeneration”, but in United States - "urban revitalization”. Also in the literature we will find the notion of "urban renewal".

Urban renewal or urban regeneration is a broad term referring to special local development actions and programs aimed at upgrading run-down urban areas. More recently, the term has also come to cover the general objectives of 'integration' or 'social inclusion', though the precise interpretation of these notions may vary from context to context. [11]

Modern attempts at renewal began in the late 19th century in developed nations, and experienced an intense phase in the late 1940 s under the rubric of reconstruction. The process has had a major impact on many urban landscapes, and has played an important role in the history and demographics of cities around the world. Urban renewal has been seen by proponents as an economic engine and a reform mechanism, and by critics as a mechanism for control. It may enhance existing communities, and in some cases result in the demolition of neighbourhoods. [21]

Urban renewal can be regarded as a tool for public policies reacting to the complexity of urban development [5]. Broadly defined, urban renewal can encompass all public and private efforts to improve city form and life. [9, p.212]

\footnotetext{
${ }^{1}$ Solidarity Fund PL in Moldova, Chisinau; Information Society Development Institute, Chisinau, Republic of Moldova; PhD student Academy of Public Administration, anastasia.stefanita@gmail.com
} 
The Revitalization Law of Poland no.1777 of October 9, 2015 defines urban revitalization as "the process of bringing out degraded areas from a crisis state, conducted in a comprehensive way, through integrated actions for the local community, space and economy, geographically concentrated, run by revitalization stakeholders based on the municipal revitalization program".[12]

The urban revitalization should have a legal base: it can be a law but it is facultative, or another kind of document (Government Decision, Public Policy, Strategy, etc.). At the local level, the city/municipality should develop their Revitalization Program that is a more practical document (including a portfolio of concrete actions - projects ideas) including as well the vision and strategically measures to be taken in order to develop the city through a concrete identified area.

A key element of the urban revitalization is identifying the most degraded area/sector of the city. The degradation do no refers only to the state of the infrastructure, but as well to the social situation (level of unemployment, deprived people, alcoholism, etc.).

The various dimensions of urban life - environmental, economic, social and cultural - are interwoven and success in urban development can only be achieved through an integrated approach. Measures concerning physical urban renewal must be combined with those promoting education, economic development, social inclusion and environmental protection. It also calls for strong partnerships between local citizens, civil society, industry and various levels of government. Such an approach is especially important at this time, given the seriousness of the challenges European cities currently face, ranging from specific demographic changes to the consequences of economic stagnation in terms of job creation and social progress, and to the impact of climate change. The response to these challenges is critical for achieving the smart, sustainable, inclusive society envisaged in the Europe 2020 Strategy. EUR 371 million is set aside for innovative actions in the field of Sustainable Urban Development over a seven-year period (2014 - 2020). [10] In this way, urban revitalization is becoming a priority of the European Union, including financial programs and instruments.

Over the past decade or so, a potentially more powerful theory for city and regional growth has emerged. This theory postulates that people are the motor force behind regional growth. Its proponents thus refer to it as the "human capital" theory of regional development. [6, p.32] In this context, we would like to define the urban revitalization as a process of cities/municipalities development through efficient local partnerships, high civic engagement and the concentration of resources in a certain area considered the most degraded in order to solve social problems of the community and bring a change with a high social impact.

\subsection{Urban revitalization and local autonomy}

In the context of the current research, the process of urban revitalization can be analysed as a dimension of the local autonomy, too. More concretely, it is a form of decisional autonomy. As was mentioned above the urban revitalization is a process based on efficient partnerships at local level. It means that local public authorities should establish partnerships with all stakeholders: business sector; civic society; citizens; other public institutions and other potential partners at the local level. As well, local authorities are free to cooperate with regional structures (for example Regional Development Agencies in the Republic of Moldova) in order to receive support in urban revitalization process, or even national/central authorities (ministries, agencies, etc.) and international donors/partners. 
In this respect, the level of local decisional autonomy should be high to facilitate in this way the creating constructive and functional partnerships.

The general local administrative autonomy is highlighted as one of the basic principles of the revitalization process. It is absolutely applied in the resource prioritisation and provision process, both: the public-administrative resources and the private or community resources identified for implementation of the revitalization activities.

The owner and the leader of the revitalization process is the local public authority (e.g. mayoralty), that's why it should have a real functional local autonomy in all dimensions and fields. Obviously, there are legal limits that should be respected but the main goal in the case of urban revitalization is the local development and a better life for citizens.

The history of urban revitalization in the United Stated involves complex interaction among the institutions, actors, and resources of both the public and private sector. Municipalities in the .U.S are somewhat autonomous and self-sufficient, especially since achieving "home rule" during the Progressive era of the early 19s. While this decentralized arrangement allots most land use authority to the municipalities, they are also obliged to provide a wide array of essential services to their residents using locally generated revenue. Despite having these robust responsibilities for the wellbeing of their citizens, however, cities' economic and physical developments have been overwhelmingly driven by private investment. Even the most aggressive attempts by government to direct urban revitalization have been geared toward providing optimal conditions for the private development of property. [22, p. 22]

Talking about Europe and different administrative systems (especially from the local autonomy perspective and the level of centralism), urban renewal is an important objective of public policies in European countries (e.g. France, Netherlands, Germany, UK, etc.). For example, in France and the Netherlands, central government involvement in urban renewal is evolving from direct intervention through sectoral subsidies, towards a "territorialized" policy. Funding for urban renewal is made available for local planning authorities in contracts with central government. These contracts are based on territorial strategies elaborated at the local level. This takes place in a context where the role of the public sector is changing. Local planning authorities become more autonomous and depend to a lesser extent on central government. At the same time, they develop a more business-like approach towards co-operation with private bodies. [23]

Besides the right of local autonomy, local authorities should have enough capacity and responsibility to manage all local issues, including an efficient cooperation relation with the business sector and other stakeholders. In ex-soviet countries, e.g. Republic of Moldova, the local autonomy is discussed more from the perspective of the rights and not - resources and real capacities. During last years, due to European integration aspirations, Moldova is promoting more active on the political agenda issues concerning real autonomy functioning in the framework of the local public administration reform based on subsidiarity and local autonomy principles.

In the same context, disinvestment, population loss and the phenomena of urban crisis that result are well known in cities all over the world, but especially in ex-soviet countries (e.g. Moldova a small country of approx. $3 \mathrm{mln}$. inhabitants, where emigration is a phenomenon - approx. 106 people are leaving daily the country [16]). More than one in four cities around the world were found to be shrinking cities between 1990 and 2000 [17]. Thus, while some cities prosper and attract people and investments, others fail to do so and experience deindustrialization, population loss and decay 
instead. The burdens of decline are, however, not carried by a handful of unfortunate peripheral cities only, but are increasingly becoming a fairly 'normal' pathway of urban development. For municipal/local governments, population losses are associated with numerous economic, fiscal, infrastructural and social problems. When jobs are lost and residents leave the city, the result is a downturn in the income available for the maintenance of urban infrastructures such as schools, houses, water networks, cinemas and grocery stores. As a result, these infrastructures become underutilized and under maintained, and often have to be abandoned. With a declining number of residents and less business to tax, local government revenues are under stress, and the ability of local government to cope with the difficulties is seriously impaired. Moreover, high unemployment leads to all kinds of problems and a need for social services that can hardly be met with limited resources. [4, p.754-755]

Urban revitalization is becoming a potential solution for this problem: by revitalising unused and underutilised spaces and turning them into places people want to live, work and play in, in order to deliver spaces that are functional, enjoyable and foster genuine connection between people and place. On another hand, urban revitalization is a good solution for another big challenge of local administration when migration from rural to urban space is high and there are overpopulated cities revitalization of peripheral areas.

Following from this, local governance arrangements need be understood as a complex interplay of macro-spatial conditions and local dynamics. [4, p.757] Also, the restructuring of nation-states and of the economy has created space for subnational mobilisation, especially at city level. [15, p.178] It is generally argued that although cities and states were highly interdependent in Western Europe, and to some extent becoming more and more so, many cities (in the sense of collective actors) have acquired and increasing sole in political and economic terms. [14]

\subsection{IT tools and urban revitalization}

Because, today, new technologies play an important, and sometimes even a central role in all human activities, IT tools do not miss from the revitalization, too. There are different ways of using e-tools within revitalization activities.

New tools created by the ICT industry have the potential to help city governments address the growing range of challenges that they are facing. Deploying ICT tools require a new discipline of digital urban renewal and a philosophy that incorporates both political leadership and open collaboration. [8, p.1]

IT tools are used efficiently from the early stage of the revitalization process. Because the communication with citizens is a very important aspect in any revitalization project, e-tools become a very useful method for achieving the main goal: communication and involving residents. This communication can be done more effective through web pages, social networks, text messaging, emails, text and video chatting, etc. Spreading important information concerning the revitalization activity to the entire community is easier to be done via electronic tools. Today is a must for all public authorities to have an updated web page where each citizen can access the necessary information on the city life. This is a transparency tool as well. Also, there are different mechanisms: electronic screens in the buildings, electronic billboards on the road in the city, mobile apps, etc. Social media is an actual way of mutual communication: authorities are publishing information and citizens interactively comments and participate in the discussion process. 
To keep informed all stakeholders on the revitalization process, usually, authorities creates special dedicated web pages and pages on the social media tools, where regularly are posted photos, videos and other kind of reports (e.g. Starachowice city from Poland: http://rewitalizacja.starachowice.eu/en/ - web page and page on social networks https://www.facebook.com/starachowiceODnowa/). [19] Following each public/civic consultation process, the local authority publishes the results and decisions on the webpage with all notes and arguments.

Besides the fact that the technologies are an efficient communication tool, IT becomes a method of revitalization. Today is absolutely possible to transform the revitalized area in a high tech centre, which becomes a business focus. "Economic growth thus requires the presence of technology, talent, and tolerance" $[22$, p. 51], that in the urban revitalization context refers to IT tools for local government, social inclusion and openness to change, new and innovation.

Because the revitalization process is an intersectorial one, "people in science and engineering, architecture and design, education, arts, music and entertainment, whose economic function is to create new ideas, new technology and/or new creative content” [22, p. 51]

Therefore, information technology plays a much greater role in communication, entertainment, and retail than before, altering the nature of demand for urban space. And building technologies have advanced. [22, p. 3] Generally speaking, "to understand the development of revitalization policy, it is necessary to recognize the marked changes in technology, demographics, and settlement patterns that threatened the aging urban giants'.[22, p. 27]

IT tools have a big role in creation of the revitalization network. The experience of Poland shows that a unique web page - portal for all cities involved in the revitalization process (20 cities included in the national program plus 3 cities selected) is efficient to ensure the equitable and equilateral communication among all stakeholders and all cities.

Besides using ICT to make existing processes involving interaction between the municipality and citizens better, cheaper, or both, ICT has a big role referring to the economic-regional development: ICT-oriented economic development or regeneration. It aims at attracting digital industries or residents that make real estate decisions based on the availability of broadband. [8, p.19] Concerning resource management - an important task of local government, the use of ICT can facilitate the improvement of functioning citywide systems to use energy and other resources more efficiently. Local authorities are improving the publics service delivering via IT tools. Today we are using e-services in different sectors: health, education, social, etc. All these are becoming part of revitalization processes when coming to citizen's life improvement issue. From the community perspective, using ICT and crowd-sourcing conduct to increasing community cohesion, or influence and improve the political system. Typically started by civil sector organizations or social enterprises.

In the context of an increasing role of ICT in urban development process, new concepts and phenomenon occur. As a result, the smart city has emerged as approach to contemporary urban planning and sustainable development. The idea of the smart city or community has a center but no clearly defined boundary. There is not even a general agreed terminology, with "smart city", "intelligent city", "wired city", "senseable city," and "smart and connected community" all used to describe similar concepts [8, p.6] There are four characterisations of cities - wired, digital, intelligent, and ubiquitous - which gives a background to the emergence of the smart city. In effect, 
it includes a digital infrastructure for communication, the 'glue', which holds the services together and enables the usage. [7, p.47/p.55]

So as urban development needs integrated and systematic approaches, including urban revitalization, we can mention another new concept and approach: digital urban renewal. At the heart of all of the different approaches is a series of programs or concepts that are aimed at making life in cities better through the use of ICT. These programs and concepts are typically a combination of: environmental sustainability; economic performance; community cohesion; efficiency of operations and/or cost reduction. [8, p.6]

Despite the widespread enthusiasm for digital urban renewal and the availability of technologies, there has been relatively little progress. The most fundamental obstacle to digital urban renewal is the limitations of municipal government. Many city governments are neither empowered nor sufficiently resourced to carry out wide-scale digital urban renewal projects (challenges mentioned above in the context of local autonomy principle). The budgets, authority, geographical boundaries, and organizational structures of many municipal authorities belong to an earlier era, and unlike comparably sized businesses, city governments are under political constraints that prevent them from conducting comprehensive restructuring programs. In addition, many are already struggling with the magnitude and complexity of the day-to-day problems that they face. Multiple and contradictory objectives and lines of accountability to central government authorities and citizens make this even more difficult. Other barriers to the introduction of digital urban renewal programs can be attributed to a fear of change, both: civil servant and citizens. Digital urban renewal also raises concerns about privacy and civil liberties. [8, p.15-16]

Due to the increasing role of the new technologies, the urban revitalization is gaining new dimensions and methods of making changes at the local level in the context of modern tendencies and diversity of the challenges that local authorities have to face.

\section{Urban revitalization in Republic of Moldova}

\subsection{Polish-Moldavian project on Urban Revitalization}

For the Republic of Moldova, the notion and concept of urban revitalization is new. It was introduced with the launch of the project "Support of the public administration in Moldova in the implementation of regional policy through sustainable and integrated urban development" in July 2017. This project is designed for the period of two years: 2017-2019. The main goal of the project is the transfer of the Polish experience to Moldova in the field of urban revitalization, so as Poland has good practises in this sector and is open to offer a real support to Moldova.

The two countries have a good collaboration history. The countries established relations following the independence of Moldova at 1991. The similar history (both were occupied by Russia and Soviet Union in various times) makes the context of development appropriate and transfer of expertise very relevant. Poland is among the first ten commercial partners of Moldova. Poland has been providing assistance to Moldova in reforming its administration and economy and has supported Moldova on its path to integration into the European Union. Moldova has been a priority country of Polish development aid since 2004. The aid measures are executed in the framework of the Multiannual Development Cooperation Programme and several projects, which cover, among others: regional development and capacity building of the national and local administration. 
The actual project is financed by the Polish Development Cooperation Program of the Polish Ministry of Foreign Affairs - Polish Aid 2017 and it is implemented by the Ministry of Economic Development of Poland in collaboration with Ministry of Agriculture, Regional Development and Environment of the Republic of Moldova with the local support of the Solidarity Fund PL in Moldova (Information Centre for Local Authorities).

The main beneficiaries of the project, at the local level, are 15 municipalities and cities. It is actually one of the first projects in Moldova that addresses to municipalities after the Law no. 764 from 27.12.2001 on administrative-territorial organization [13] was updated and approved a new list of 13 municipalities. The project includes 10 of them (besides Chisinau - the capital; Bender and Tiraspol - from the left bank of Nistru River). Additional to 10 municipalities, in the project were invited 5 more cities (Ialoveni, Cimislia, Causeni, Edinet, Briceni) that have a good potential of development based on the number of population, geographical position, capacity to attract funds and good experience in project implementation, as well as a presence of a big need of urban revitalization.

The project supposes creating efficient support system for effective urban development and renewal of cities, on one of the hands, and on another one - improving quality of development projects in cities including regulatory, institutional and financial instruments through developing, testing and piloting of programs and projects for urban regeneration.

The action includes two level interventions:

- at national and regional level - to provide technical assistance/policy advise to develop existed and/or draft new instruments and mechanisms dedicated to cities and renewal of cities and to implement them finally;

- at the local level - to provide advice and enhance skills for cities to develop and adopt urban renewal programmes and to identify and implement projects. [18]

The approach of the urban revitalization in the Republic of Moldova has two main directions that should go on in a parallel way. On one of the hand, there should be a bottom-up approach, cities having the main role in the implementation of urban revitalization process; and on another hand there is necessary to update and renew legal provisions by including the notion of urban revitalization in the legal framework, which is mainly under the responsibility of the Ministry of Agriculture, Regional Development and Environment of the Republic of Moldova. In this context, this parallel approach should conduct to revision and developing the legal and institutional framework and to the participative process through involvement all relevant stakeholders at local level.

Also, a central point is drafting the renewal programmes and projects at the cities level. Logically, based on the general-national legal framework that provides the general directions and priorities, cities and municipalities will develop their "Urban Revitalization Programs". These plans are different than "General Urban Plans". The main differences between these two plans, both very important for cities, are: General Urban Plan refers to the entire territory of the city but the Urban Revitalization Program is focused on a concrete area of the city - the most degraded sector; the General Plan is focused mostly on the infrastructure issues but the Urban Plan should be oriented to a high social impact. For drafting and implementing the Urban Revitalization Program is very important to establish efficient partnerships and to get involved the citizens. Also, involvement of 
the local business sector in the process has a crucial role. Generally speaking, the General Plan has mostly the hard component, while the Revitalization one is focused on the soft one.

\subsection{The readiness of cities and municipalities to undertake urban revitalization activities}

The main goal of the revitalization process is to revive the identified depraved area not only from the infrastructure point of view but also from the social one. The objective is to attract people and to facilitate different processes, activities to be organised in this area. In this context, is very important the readiness of the cities to undertake urban revitalization activities.

Within the project, during August - September 2017, cities involved in the project activities, filled in a questionnaire. The goal of the activity was to obtain information from a local perspective - both on the functioning of regional development mechanisms at local level, as well as on the specific conditions of each locality, the achievements, the problems and the expectations in the context of the theme and the scope of the project.

The analysis of individual responses shows that the questionnaires were completed by people with different professional profiles and perhaps with different opinions on priorities, directions of urban development and the role and significance of different strategic documents. Differences are also noted in the fact that some of the answers are of a very formal nature and should be considered as "official optimism", while others indicate greater freedom of expression. All of these factors may affect the completeness and validity of statements. Therefore, it is difficult at this stage to objectively state in which cities it is bigger and where there is less potential (primarily social and institutional) for undertaking revitalization activities. On the other hand, it is clear that this potential exists in the interviewed cities, and a reliable approach to completing the questionnaire shows that cities have significant hopes in implementing this project. [1]

Regarding strategic documents and planning, cities consider consistently the most important socioeconomic development strategy of the city and the general urban plan. In most cases, cities claim that their institutional capacity is sufficient to undertake local development and urban renewal. Similarly, staff fluctuation is not a significant issue. Although the number and potential of social organizations in different cities are varied, it is clearly visible that they are actively involved in the city life. Another answer, containing the most interesting examples of recent activities by civic organizations, shows that in most of the interviewed cities, social organizations have been entrusted (or even have begun) with major public policy actions, especially in the field of social policy. This will undoubtedly be a good basis for including social organizations in revitalizing activities.

Also, the questionnaires allowed to make a mapping of resources and the development directions of the cities on five pillars: social sphere; infrastructure (including the social one as well); water and green spaces; energy efficiency of the buildings; the life quality in the city. Among the social issues, cities have a special focus on actions related to children and youth. This may be a sign of the desire to stop the younger generation from emigrating. The agreement of the cities in this regard should suggest the need to include this topic at national level.

In the same context, all cities could identify easily the most depraved area in their locality. [1]

Another project activity for increasing the level of cities readiness for revitalization processes are workshops that were organised during October - November 2017 and where participated 2-3 representatives from each city: local public authorities (mostly architects, deputy-mayors, 
responsible for attracting investments, etc.) and local civic society (schools, active citizens, local NGOs, etc.). The aim of the workshops were to inform the local representatives on the revitalization concept and process based on the Polish experience, but also on good European practises and lessons learnt. During workshops, local representatives could work on concrete tasks in order to train the social oriented revitalization activities identification. Also, a good impact was the possibility to exchange the local practices among cities and municipalities from Moldova within the organised workshops. In this way, local representatives could get inspired from experience of other Moldavian cities (as show the results of the workshops evaluation by the participants). [2]

\subsection{Legal framework on Urban Revitalization in the Republic of Moldova}

As was shown above, the owner of the urban revitalization process in the Republic of Moldova at the central level is the Ministry of Agriculture, Regional Development and Environment. Within the mentioned project, the Ministry is developing, with the strategic-conceptual support and advisory from the Polish side, the first note-document entitled "Assumptions of the Urban Revitalization in the Republic of Moldova". The mentioned document will be developed at the next phase in a more comprehensive one: "Guidelines of the Urban Revitalization", that actually will represent a policy document.

The assumptions define the general context of the new concept and process in Moldova. The first draft of the document stipulates that the revitalization comes out from the following cities necessities:

- rehabilitation of the heritage of the historical districts, to facilitate organisation the socialcultural events for population in the region;

- $\quad$ improving life conditions in blocks of flats;

- $\quad$ refurbishment and embellishment of the public space - squares, parks, etc. combined with new social activities for citizens;

- $\quad$ upgrading urban infrastructure - from water, gas and electricity networks to roads and public transport networks; including the soft aspect as well.

These actions are to be part of the regional development policy priorities through specific policies and programs. [3]

Urban revitalization is generally defined as follows: "Bringing urban areas to life with the cooperative effort of municipalities, owners and other stakeholders to improve living conditions, enhance environmental and social climate and strengthen the local economy." According to this definition, urban regeneration has 3 pillars: physical, economic and social. Depending on the situation in the area, we need to refer more or less to the three pillars when developing an urban revitalization program. Also, the "Assumptions" document answer to such questions as: why we need the urban revitalization; what does mean this concept for Moldova. It establishes the short and long term objectives, identifies the stakeholders and their roles and shows which funds can be used for revitalization projects at local level. [3]

The guideline will be large consulted with all stakeholders including cities, civic society, etc. 
The main idea is that there will not be concrete indications from the centre level, but the local autonomy should be functioning in order to be able for updating the local development plans and documents from the revitalization perspective. The urban revitalization represents in this context, an exercise for the local autonomy of the cities from the Republic of Moldova.

\subsection{Piloting phase on Urban Revitalization projects}

The very first actions of urban revitalization in the Republic of Moldova will be organised within the piloting phase of the mentioned above project during the 2018 year. After several trainings and study visits in Poland, the responsible persons from the cities of Moldova, based on the polish inspiration, will design project ideas on urban revitalization process. The call will be public but will refer to the cities involved within the project. As a result will be implemented 5-6 projects of urban revitalization.

The evaluation criteria were discussed and consulted with the participants based on the bottom-up approach. All cities were involved in the consultation process. [20]

Parallel with the piloting phase will be organised the elaboration process of urban revitalization programs of the cities. This process will be facilitated by special selected coachers together with the experts from all 4 Regional Development Agencies from Moldova. This will ensure the sustainability of the revitalization process under the guideline of the Ministry of Agriculture, Regional Development and Environment of Moldova.

Based on the results of the piloting phase, in 2019 will be applied a larger financing scheme for urban revitalization projects involving different donors and stakeholders.

\section{Conclusions}

Urban revitalization represents a complex and integrated process. It involves different stakeholders and requires a high level of local autonomy in terms of capacities and good management. An important step in urban revitalization process is the identification of the degradable area based on a comprehensive diagnostic/analysis of the local situation. The process supposes a high level of the participatory and civic engagement.

In the Republic of Moldova the first steps of urban revitalization are done within the bilateral project with Poland. The Polish experience is very relevant for Moldavian cities so as these two countries have a lot of similarities in terms of history, economic development and good bilateral relations. The urban revitalization process in Moldova implies 3 parallel processes: national level (guidelines document with the role of regulation); piloting phase (implementation of 5-6 projects in cities); urban revitalization programs (at the local level).

The new technologies are used as communication but also an implementation tool in the urban revitalization process. 


\section{References}

[1] Analysis of questionnaires addressed to cities in the Republic of Moldova and Ministry of Agriculture, Regional Development and Environment of the Republic of Moldova on the conditions for the development of urban revitalization and renewal activities. "Pojekty miejskie" experts. Warsaw, October 2017.

[2] Analysis of urban regeneration trainings evaluation (October - November 2017, Chisinau, Republic of Moldova).

[3] Assumptions of the Urban Revitalization in the Republic of Moldova (draft document). Ministry of Agriculture, Regional Development and Environment of the Republic of Moldova.

[4] BERNT, M.: Partnerships for Demolition: The Governance of Urban Renewal in East Germany's Shrinking Cities. International Journal of Urban and Regional Research, Volume 33.3, September 2009.

[5] COUCH, C., FRASER, C., \& PERCY, S. (Eds.): Urban regeneration in Europe. Blackwell Science, 2003. 227 p.

[6] FLORIDA, R.: Cities and the creative class. Routledge. New York, 2005. 198 p.

[7] GRANATH, M.: The smart cities - how smart can 'IT' be? Discourses on digitalisation in policy and planning of urban development, Linkoping Studies in Arts and Science No. 693, LiU, Sweden 2016, 226 p.

[8] GREEN, J.: Digital Urban Renewal, OT00037-004, Ovum, 2011. 30 p.

[9] GROBERG, R.P.: Urban Renewal Realistically Reappraised. In: Duke Law Scholarship, CGI.

[10] Integrated Sustainable Urban Development chapter of the European Cohesion Policy 20142020, European Commission, 26.03.2014.

[11] KERESZTÉLY, K.: Urban Renewal as a Challenge for European Urban Development in the 21st century, 2016. Available on: 'cities territories governance' http://www.citego.org/bdf_fiche-document-532_en.html (visited on March 4, 2018).

[12] Law no. 1777 of 9.10 .2015 on Revitalization. Dz.U. 2015 poz. 1777. Kancelaria Seimu, 04.11.2015.

[13] Law no. 764 of 27.12.2001 on administrative-territorial organization of the Republic of Moldova. Official Monitor No. 16, art. 53, 29.01.2002.

[14] LE GALES, P. and HARDING, A.: Villes et Etates en Europe, in V. Wright and S. Cassese. (eds), La restructuration de 1'Etat en Europe. La Decouverte, Paris, 1996.

[15] LE GALES, P.: Cities in Contemporary Europe, edited by Arnaldo Bagnasco, Cambridge University Press 2000. 178 p. 
[16] National Bureau of Statistic of the Republic of Moldova, www.statistica.md (visited on March 4, 2018).

[17] OSWALT, P. and RIENIETS, T.: Atlas of shrinking cities. Hatje Cantz Publishers, Ostfildern-Ruit, 2006. 160 p.

[18] PRAGERT, G.: Polish-Moldavian Project presentation. Project Coordinator, Department of Assistance Programmes, Ministry of Economic Development of Poland. Chisinau, Republic of Moldova, October 2017.

[19] Starachowice Revitalization web page http://rewitalizacja.starachowice.eu/en/

[20] Study visit in Poland, December 2017, http:/www.centruinfo.org/2017/12/11/vizita-destudiu-in-polonia-revitalizare-urbana/ (visited on December 14, 2017).

[21] Urban Renewal, https://en.wikipedia.org/wiki/Urban_renewal (visited on November 26, 2017).

[22] Urban Revitalization in the United States: Policies and Practices. Final report. United States Urban Revitalization Research Project (USURRP). 25 June 2008. Available at: http://www.columbia.edu/cu/c2arl/pdf_files/USURRP_Phase_I_Final_Report.pdf (visited on November 26, 2017).

[23] VERHAGE, R.: Towards a territorialized approach to urban renewal: A comparison of policies in France and the Netherlands, Journal 'International Planning Studies' Volume 10, 2005 - Issue 2, p. 129-143. 